At the same time we will have to continue to understand better than currently the impact of human activity on the atmosphere, by working to eliminate the uncertainties and tailoring our controls to fit the realities. UNEP will ensure through the CCOL that the scientific review and assessment process will be a continuing one-so that, should science so dictate, a prompt response can be determined and the protocol duly revised. With good faith, willingness to cooperate and accommodate, and some statesmanship, the ozone protocol can be achieved-in the spirit of the very recent signing in New Caledonia by 16 diverse metropolitan and small-island states, split earlier by serious political differences, of an agreement on protecting the natural resources and environment of the South Pacific.

\title{
The Road Ahead
}

After more than a year of re-examination, the task of achieving this much-needed protocol cries out in importance but is fraught with difficulty. In the simplest terms we have to decide on those measures which Mankind can take now to preserve the basic characteristics of the atmosphere that comprises so much of the fundamental life-support system of our planet-by acting to prevent large and irreversible changes to the stratospheric ozone layer. This is no minor task but one of the most momentous imaginable, our goal being the adoption of a fully safeguarding protocol. It can and must be accomplished in the months ahead because of the sense of concern which we all share about the safety of the fragile ozone shield. So let us concentrate on the task at hand and proceed with a common design to arrive at a protocol with the least delay possible.

In 1962, the late President Kennedy of the United States paid a state visit to Canada during which he and the then Prime Minister, John Diefenbaker, undertook a small environmental task-a tree-planting ceremony-during which the President strained his back. Learning of the injury later, the Prime Minister sent a sympathetic letter to the President, who replied: 'Dear Mr Prime Minister: Thank you for your thoughtful letter. The tree will be there long after the discomfort is gone.' As we begin the important task before us, we know that the results of our work will be there to benefit Mankind long after the burden of effect is forgotten. Let us accordingly do all we can to ensure that The Biosphere's ozone shield remains intact to protect life on Earth.

William H. Mansfield III, Deputy Executive Director United Nations Environment Programme (UNEP)

P.O. Box 30552

Nairobi

Kenya.

\section{NOTICE}

\section{4-86 Cumulative Index of Titles and Authors in Environmental Conservation}

$\overline{-}$ ollowing our preliminary notice of the above, on page 194 of our latest issue, we have had encouraging correspondence, donations, and even incipient orders, but not yet enough to go ahead with full confidence with what we are assured would be a very worthy and helpful project of publication. A few more donations to back indications of need, and/or sale of complete sets of the 13 volumes of the Journal published to date, would secure our positive decision on the matter of printing forthwith, as the Index is now complete and being revised and edited for full conformity.

We are further assured that such a publication would indeed document very 'much of the evolution of the environmental movement during its most vital, formative period', as well as much of the world's conservational thrust, and that we should be able to keep the price down to 30 Swiss Francs or 20 US dollars (inclusive of postage) which we would certainly hope (though not yet guarantee) to do.

(Mrs) LYNN CuRMe

Environmental Conservation

7 Chemin Taverney

1218 Grand-Saconnex

Geneva, Switzerland. 